\title{
Preface
}

T O S P E A K of mind regained is to imply that mind has been lost. But in this century, in which mind has accomplished such wonders in science and technology, how can it be plausibly implied that mind has been lost? In the course of the twentieth century, the power of mind's functions has revolutionized the study of physics. It has unleashed on this planet the terrible energy that drives the sun and the other stars. It has flung about the planet and indeed about the entire solar system an electronic web so delicate and precise that by virtue of it some of us have walked on the moon, and all of us have been able to inspect, as it were at close range, the moons of Jupiter and the rings of Saturn. That power has constructed and stationed in the clarity of space a telescope whose unexampled reach has opened to our sight an intergalactic vastness far greater than that imagined space whose silence so frightened Pascal. It has constructed a complex blend of intricate theory and instruments that has allowed us to "see" into some of the most fine-grained energy transactions of nature; it has produced another complex of theory and instruments that allows us to "see" (and to aspire to control) the minuscule logical structure of living matter. In all these achievements the power of mind's manifold functions seems only now to be coming into its maturity. In such a time how can it even be suggested that mind has been lost?

My title, I concede, is an exaggeration. But something profoundly important to mind's well-being has indeed been lost, and lost by the very persons who should have been most zealous to preserve it--I mean the most influential workers in academic philosophy, cognitive science, and neurophysiology. Mind, as represented by this group of philosophers and scientists, has failed to see that it operates as a real cause within and upon the material world, and that this real causality is the source of all the theoretical and physical devices that have made possible all the wonders I mentioned. Mind, as represented by that influential body of persons, has lost an adequate understanding of the very functions by virtue of which it accomplishes both its everyday and its more exalted tasks. It 
has failed in self-knowledge and so has lost resources that are still there to be found.

This failure in self-knowledge on the part of a powerful intellectual establishment has had a negative influence on those educated people who do not belong to that establishment but follow its pronouncements because they find the mind-body problem interesting and important. These members of a wider intellectual community have as a consequence been unwilling or unable to look at their own minds in action and find there what has been left out of that establishment account. This book is aimed in part at that wider public in the hope of bringing about a new self-consciousness on the part of mind as it manifests itself in their persons. In this book I call that kind of intellectual enterprise attending to mind itself.

In a preface it is appropriate to speak both roundly and simply about the reasons for the loss I perceive. I single out just the two most important reasons. The first is a failure of philosophy over the centuries rather than a failure in the confluence of philosophy, cognitive science, and neurophysiology I have been calling an establishment. The current of philosophy running from Descartes through Kant and down into contemporary empiricism has predisposed most contemporary philosophers to what I call in this book a negative philosophical judgment about the powers of the human mind. That judgment lays it down that the mind has no direct reality-attaining function but must make do instead with a groping and always-frustrated approach to the real that begins in ideas and then makes its way by constructing theories about that which is not directly accessible.

The second reason is the prevalence in both philosophy and science of what I call the received scientific doctrine of causality. Because of that, the influential and talented writers I describe as an establishment have been determined for much of this century to provide an explanation for the mind of which they, the reader, and I are instances. But they are also determined that no explanation of mind shall be regarded as adequate unless it displays mind as an effect of the physical entities and events that science investigates so superbly. An acceptable explanation must therefore exclude any apparent causality on the part of mind that resists explanation in terms of the doctrine of causality that prevails in science.

Many important things that seem to lie in the province of mind resist explanation in terms of that doctrine. The greatest works of the mind in science, the arts, and morals are pervaded by rational, esthetic, and moral modes of order that make up the very content of those works. The works have the structure they do have in order to make manifest just those particular modes of order. In any particular work-whether of science, art, or morals--its mode of order 
mandates the particular steps that are necessary to produce the order the person who makes the work is aiming at. We therefore cannot leave reasons (in a sense broad enough to comprise science, art, and morals) out of any really searching causal account of the genesis of such works; and we cannot leave out a mode of causality that mind itself appears to exercise in discerning reasons (in this broad sense) and weaving them into the articulation of the work. Despite all this, the establishment resolutely proposes to set aside all such apparent causes as merely apparent, and to replace them with causal accounts couched in terms of what I call in this book the received scientific doctrine of causality.

I am sure that these brief remarks on the negative philosophical judgment and on the received scientific doctrine of causality are too compact to be satisfactory, but both themes are developed in a leisurely way in the book itself, and the long introductory chapter that follows this preface provides a clear approach to the program of the book. To that wider educated public I hope to reach I would add this consoling thought: attending to mind itself- the objective of Part Two-is essential to regaining what has been lost, and though attention of that sort is not easy, it is by no means a matter that must be left to professional philosophers and professional students of the mind.

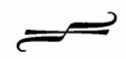

While Cornell University Press was considering the manuscript of this book, three friends, Barbara S. Held, Alicia Juarrero, and Theodore A. Young, read that manuscript and made useful and encouraging comments. Although the argument and structure of the book remain what they were, those comments have led to several local changes that make for greater clarity in what is now before the reader. I am grateful to these friends for their generous help. Held, who is well known for making realism a new and vital force in theory of psychotherapy (1995), brought to her comments (and to our many conversations as this book developed) a sound philosophical perspective, but one from outside the field of academic philosophy, and this has helped me in my effort to make this book accessible to a wider audience. Another friend, Louis Dupré, has played a larger role in the development of the book than perhaps he knows: his enthusiastic and perceptive response to an early version of Part Two helped assure me that there was something useful in what I was trying to say, for he is a person who speaks with authority about philosophical matters. I thank him for that generous support.

Finally, I am happy to say in a public forum of Roger Haydon, editor at Cornell University Press, what I have already said privately: he made it clear to me why an earlier version of this work did not fulfill my aim of writing something 
both philosophically rigorous and accessible to a cultivated readership outside the field of academic philosophy. His advice about that and other matters has always been precise, unswerving, yet tactful. If this book is now closer to what I was aiming at, he deserves a large measure of the credit.

Edward Pols

Brunswick, Maine 


\section{Mind Regained}


